\title{
Two-phase Airlift Pumps in Biological Systems
}

\author{
Thariq Mohammed ${ }^{1}$, Johnathan Szeliga ${ }^{2}$, Wael H. Ahmed ${ }^{1}$ \\ ${ }^{1}$ School of Engineering, University of Guelph \\ 50 Stone Road E, Guelph, ON, Canada \\ thariq@uoguelph.ca; ahmedw@uoguelph.ca \\ ${ }^{2}$ Animal Science \& Nutrition, University of Guelph \\ 491 Gordon St, Guelph, ON Canada \\ jszeliga@uoguelph.ca
}

\begin{abstract}
Airlift pumps operating under two-phase flow conditions have been used in biological systems for aeration while pumping water simultaneously. In this paper, airlift pump is integrated in aquaponics that consists of a traditional Recirculating Aquaculture Systems (RAS) with a hydroponics system as an integrated biological system for producing fish and plants. The effect of using airlift pumps operating under two-phase flow conditions on the mass transfer capability in the system is experimentally investigated. The results show a great potential of airlift pump in the aeration process while striping carbon dioxide. Moreover, an optimum air flow rate while operating the pump at the best efficiency point is also achieved.
\end{abstract}

\section{Introduction}

Airlift pumps work on the principle of buoyancy by injecting a gas into a pipe submerged in liquid medium. The gasliquid mixture inside the pipe will have a lower density than that of the surrounding liquid medium causing a lifting effect moving the liquid along with the mixture. There are many reasons why this pump is beneficial over other conventional technologies, including low maintenance, simplicity and low initial cost [1]. Also, the lack of moving parts makes this pump more reliable than conventional centrifugal pumps. The principle of airlifts has been known and used since 1797, when a German engineer used air to lift up slurries from a coal mine shaft [2]. However, there are limitations to the conventional airlift pumps, including low flow rates and the requirement of a high submergence. Currently there is ongoing research to mitigate these issues, including testing of a newer airlift pump that uses a patented dual injection design developed by [1].

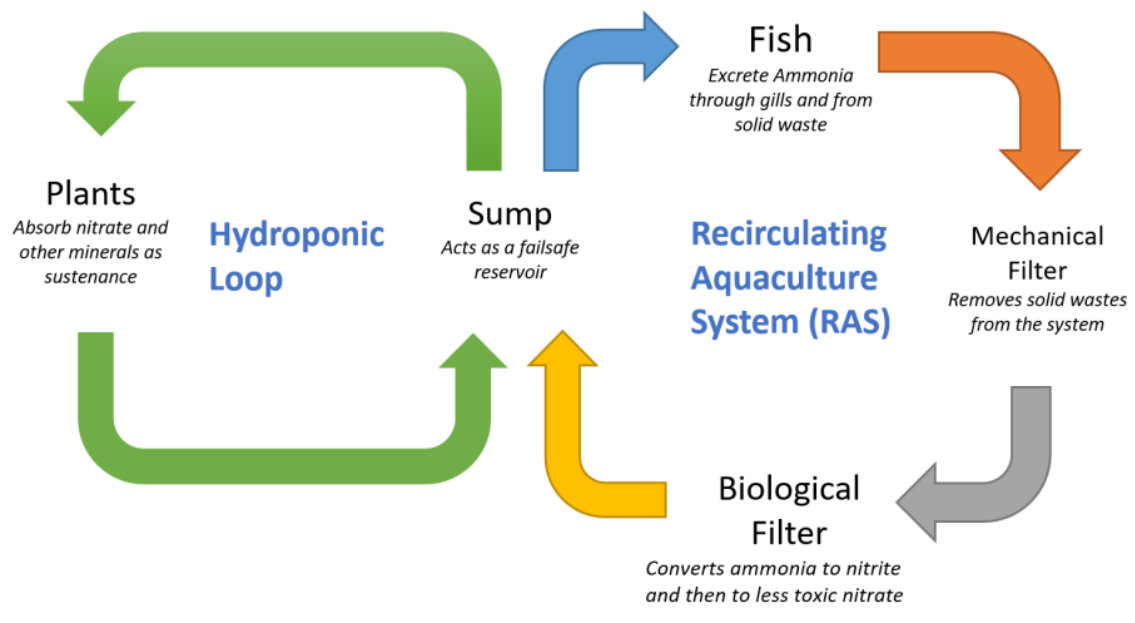

Fig. 1: Aquaponics Cycle. 
Among the many applications of the novel airlift pump, its use in biological aquatic systems is highly promising. This is because of the airlift pump ability to simultaneously move water while mixing media and aerating the liquid; thereby reducing power consumption considerably by removing the need for additional technology that would perform these tasks in conventional systems. This paper will specifically talk about the integration of these novel airlifts in aquaponics systems. An aquaponics system is an integrated food production system that combines traditional aquaculture practises with hydroponic food production. The basic concept of aquaponics is that the waste produced by fish, which in high quantities would be toxic to them, gets treated to become nutritious for plants and will help them grow. The fish in turn get cleaner water, reducing the need for constant water changes. A recirculating aquaculture system consists of growing animals (mostly fish) in a constant water circuit to reduce water consumption. The main parts of the aquaculture system are the mechanical filter which collects any solid fish waste, the biological filter that provides an ideal environment for nitrogen-fixing bacteria to colonize, and a pump that provides the required flow to maintain good water quality for the fish.

A major component of the fish waste consists of the nitrogen compound ammonia. This chemical is converted in the system to nitrite with the help of autotrophic bacteria like nitrosomonas. Nitrite however is still toxic to fish and is once again converted in the system to nitrate with the help of nitrobacters. [3]. The plants then absorb the nitrate as a nutrient [4].

Water flow rate through the system is an important parameter in aquaponics. This flow rate determines the amount of waste transfer from the fish tank to the proceeding filters. A low flowrate can lead to the accumulation of the waste to toxic levels in the fish tank. Fish can also be negatively impacted by high flowrates but this is seldom seen in aquaponics. There are many papers which talk about flowrates in aquaculture and aquaponics [4-6]. A fish tank turnover time of 2 times an hour for heavily stocked tanks is the accepted industry standard. However, for lightly stocked tanks, the flow rates can be as low as 0.5 to 1 times an hour $[4,5]$.

The pumps will also need to maintain certain water quality parameters in order for them to not pass any toxic threshold for the fish, with this threshold varying slightly depending on species. For the fish to be used in this experiment, Nile tilapia (Oreochromis niloticus) found to be the ideal species for the current water quality conditions summarized in Table 1.

Table 1: Optimal ranges for maintaining healthy tilapia in an aquaponics system.

\begin{tabular}{|c|l|}
\hline Water Parameter & Optimal Range \\
\hline Alkalinity & $<100 \mathrm{mg} / \mathrm{L} \mathrm{CaCO}_{3}$ \\
\hline Ammonia & $<1 \mathrm{mg} / \mathrm{L}$ \\
\hline Carbon Dioxide & $<60 \mathrm{mg} / \mathrm{L}$ \\
\hline Nitrite & $<1 \mathrm{mg} / \mathrm{L}$ \\
\hline Nitrate & $5-150 \mathrm{mg} / \mathrm{L}$ \\
\hline Oxygen & $5-10 \mathrm{mg} / \mathrm{L}$ \\
\hline pH & $6.4-7.4$ \\
\hline Temperature & $27-29^{\circ} \mathrm{C}$ \\
\hline Water Hardness & $50-100 \mathrm{ppm}$ \\
\hline
\end{tabular}

One aspect of water quality that airlifts can have an impact on is dissolved carbon dioxide $\left(\mathrm{CO}_{2}\right)$ content. The presence of this chemical in an aquaponics system needs to be monitored to ensure that it does not reach toxicity level for the fish. Although the content of the $\mathrm{CO}_{2}$ will gradually accumulate due to metabolism of the fish and bacteria, it can be removed from the system with the aid of airlift pumps [7, 8]. By releasing air bubbles underwater and causing turbulence in the pump's water column, this increases the amount of surface area the water has to atmospheric air which will have a lower $\mathrm{CO}_{2}$ level then the surrounding liquid. Thus, through exposing a greater amount of water to this gas the rate of $\mathrm{CO}_{2}$ diffusion back into the atmosphere is increased, and the levels in the aquaponics system decrease to avoid reaching toxicity for the fish. 


\section{Experimental Setup}

A midscale aquaponics system was designed to test the performance of the airlift. The system was redesigned from conventional aquaponics systems to integrate the airlift design. The system was designed with 2 airlift pumps, 1 supplying aeration and flow to the recirculating aquaculture system (RAS) while a smaller pump provides aeration and water flow to the hydroponic component in the system.

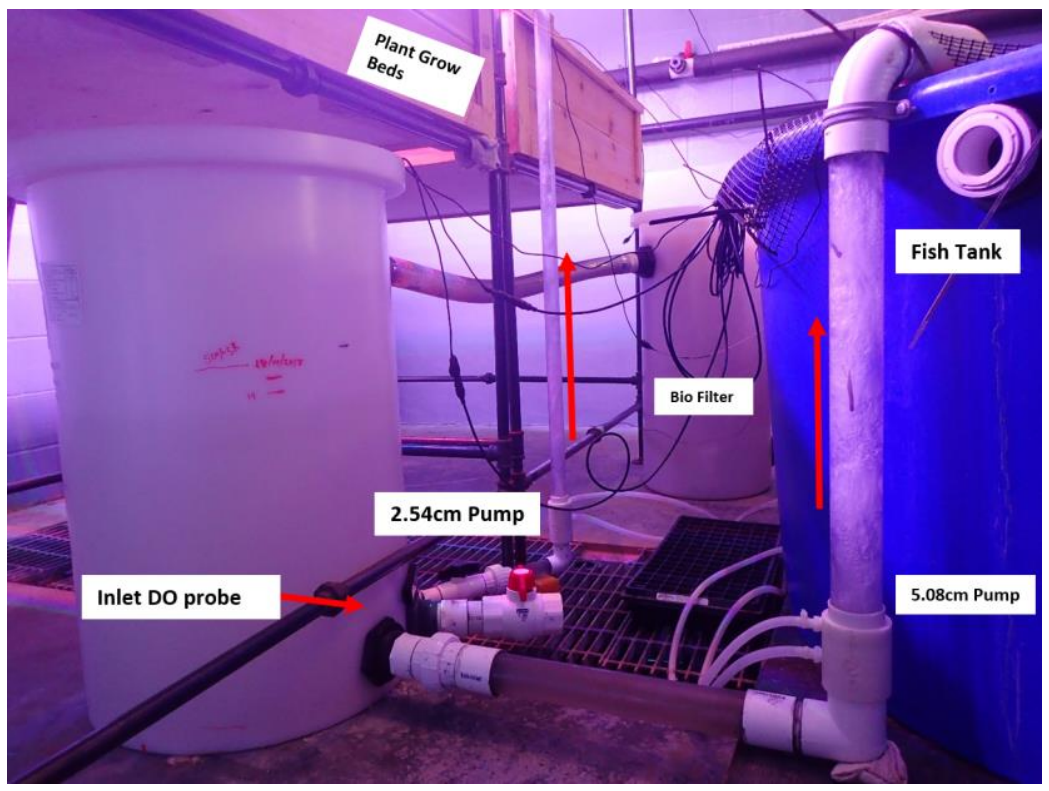

Fig. 2: Experimental Setup with airlift pumps installed.

The system consists of a 1500 litre fish tank that drains into a radial type mechanical filter. The 114 litre mechanical filter drains directly into the biological filter (114 litre). These filters are filled with K-1 media that provides the surface area for bacterial to colonize. An air stone is introduced in the biological filter to keep the bacteria healthy and to provide a fluidized bed motion. The bio filter drains into the 208 litre sump tank. The two airlifts use the sump as an inlet and provides the water requirements for the RAS and the hydroponic systems. A $5.08 \mathrm{~cm}$ diameter airlift pump provides the flowrates and aeration to the RAS system while a $2.54 \mathrm{~cm}$ pump provides the flowrate and aeration to the hydroponic loop. The entire system is powered by 2 LAM-200 blowers that when combined provides the system with an air flow rate of 184 LPM.

\section{System Design}

The pump size was determined using the airlift model mentioned in [9]. The flow rate required in the RAS system is in the range of 12.5 to 25.2 LPM. This is based on the total volume of the fish tank and a turn over time of 1 to 2 hours for a lightly stocked system [4], [5]. A 5.08cm airlift pump at a submergence ratio of $40-50 \%$ is sufficient for this aquaponics setup. The model predicts an air-flow rate of 85 LPM to receive an output water flowrate of 12.6 LPM and 161 LPM of air to output 25 LPM of water for a $45 \%$ Submergence Ratio. The hydroponic loop requires low flow rates that can be provided by a $2.54 \mathrm{~cm}$ pump. The flowrate required for this system equates to $1 \mathrm{LPM}$. According to the model, the $2.54 \mathrm{~cm}$ pump requires about $65 \mathrm{LPM}$ of air input to achieve this goal.

In any aquaponics system design, the most important parameter to consider is the dissolved oxygen that will be provided by the blowers. The amount of fish in the system is based on the potential of the airlifts to provide dissolved oxygen to the system. A preliminary test was performed to estimate the amount of oxygen that a $5.08 \mathrm{~cm}$ pump will provide. The oxygen level at the tank is measured using a handheld Oxyguard Dissolved Oxygen sensor. The pump is then turned on and the pumped water is collected and the DO level in the collected water is measured. The data collected from this initial experiment is used to calculate the amount of fish that goes into the system. The amount of plants being planted in the aquaponics system is derived from the amount of feed put into the system. In aquaponics, the amount of feed 
provided to the system is a direct indication of the nutrients that will be entering the system and hence, is a good indication to calculate the amount of plants the system can handle.

Table 2: Aeration results of the $5.08 \mathrm{cmgallo}$ pump prior to system setup.

\begin{tabular}{|c|c|c|c|c|c|}
\hline $\begin{array}{c}\text { Oxygen in } \\
\text { sump (mg) }\end{array}$ & $\begin{array}{c}\text { Oxygen in } \\
\text { Bucket (mg) }\end{array}$ & $\begin{array}{c}\text { Mass } \\
\text { Transfer }\end{array}$ & Time & $\begin{array}{c}\text { mg } \\
\text { O2/sec }\end{array}$ & $\begin{array}{c}\mathbf{g} \\
\text { O2/day }\end{array}$ \\
\hline 6.48 & 14.99 & 8.51 & 10.01 & 0.85 & 73.45 \\
\hline 6.60 & 15.43 & 8.83 & 10.02 & 0.88 & 76.14 \\
\hline 7.00 & 23.40 & 16.40 & 20.00 & 0.82 & 70.85 \\
\hline 7.13 & 17.10 & 9.97 & 10.11 & 0.99 & 85.20 \\
\hline 7.12 & 16.52 & 9.40 & 10.35 & 0.91 & 78.47 \\
\hline 7.92 & 16.20 & 8.28 & 10.08 & 0.82 & 70.97 \\
\hline
\end{tabular}

Based on the results of the airlift, the size of tilapia being introduced to the system and their daily oxygen consumption, the total number of tilapia for the aquaponics system was estimated to be 40 fish that is estimated to grow to $200 \mathrm{~g}$ in size in a 2-month period. A vast majority of water quality parameters is monitored throughout the growth period. In this paper, the two major parameters that will be mentioned are Dissolved Oxygen and Dissolved Carbon Dioxide introduced and stripped to and from the system by the Flonergia $\odot$ airlift pumps.

\section{Results}

Data is collected every 15 minutes for the whole period of the experiment. Fig 3 shows a sample of the data collected from this aquaponics setup on February $17^{\text {th }} 2018$. On average, the $2.54 \mathrm{~cm}$ pump is adding $2.86 \pm 0.90 \mathrm{mg} / \mathrm{L}$ of dissolved oxygen to the water. This pump has a constant flow rate of 1.2 LPM which equates to a total oxygen addition of 4.94 $\mathrm{g}$ /day. The system temperature ranged between 25 and $27^{\circ} \mathrm{C}$. Thus according to Henry's law for solubility of gases, a DO saturation of around 8 to $8.30 \mathrm{mg} / \mathrm{L}$ is expected for this temperature range. However, the average DO level at the $2.54 \mathrm{~cm}$ pump exit is $8.20 \mathrm{mg} / \mathrm{L}$. Hence, saturation is reached with the $2.54 \mathrm{~cm}$ pump when an average inlet DO level is at 6.09 $\mathrm{mg} / \mathrm{L}$. The effect of lower inlet DO levels will be monitored in the future as the fish and plant DO requirements will change resulting in lower DO levels further in the experiment.

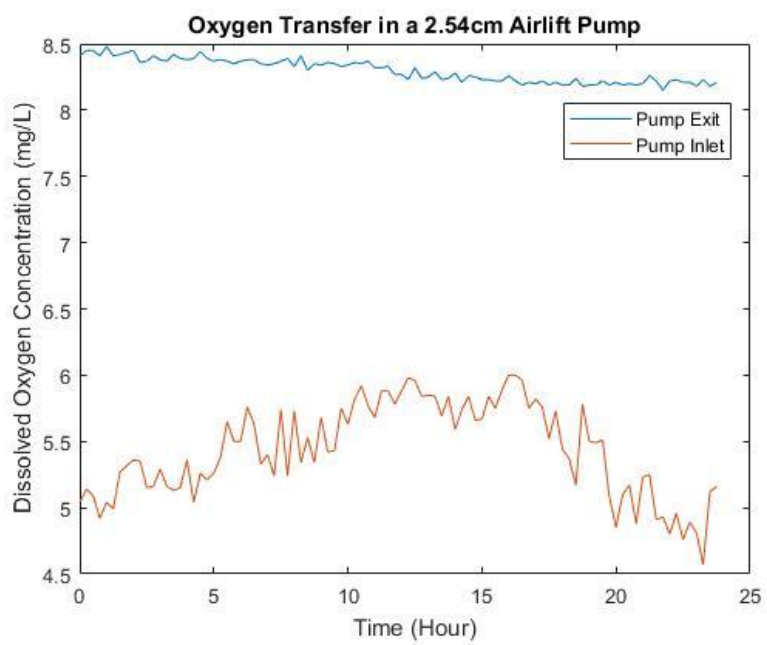

a. Aeration for $2.54 \mathrm{~cm}$ pump (Feb 172018$)$

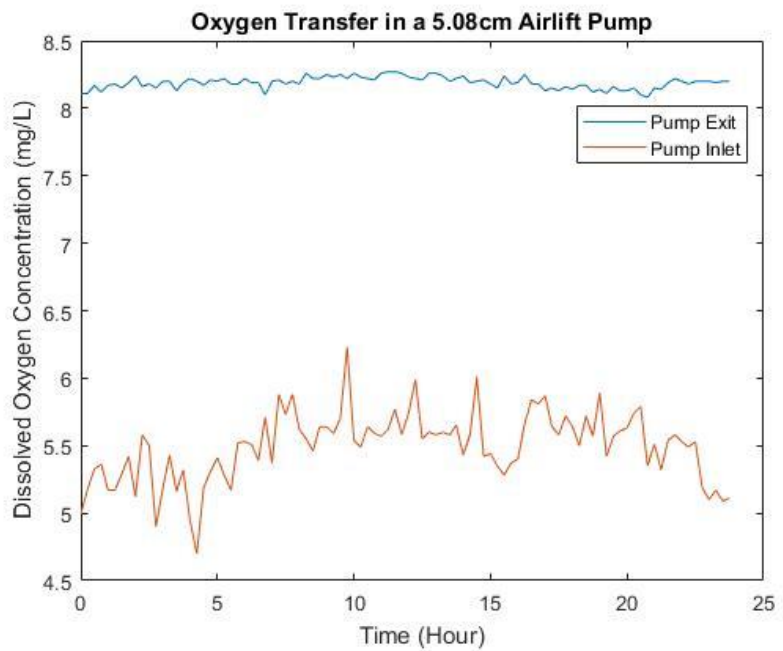

b. Aeration for $5.08 \mathrm{~cm}$ pump (March 5 2018)

Fig. 3: Aeration results u the airlift pumps. 
The $5.08 \mathrm{~cm}$ airlift pump was consistently adding $2.70 \pm 0.25 \mathrm{mg} / \mathrm{L}$ of oxygen to the water. The total water flow rate of the $5.08 \mathrm{~cm}$ pump is $20.8 \mathrm{LPM}$ at an air injection of 124.6 LPM. Hence, the total amount of oxygen added by the pump per day is $80.05 \mathrm{~g} \mathrm{O} 2 /$ day which is consistent to that of the initial tests done on the pump which predicted the DO addition to be on a range of 70 to $85 \mathrm{~g} \mathrm{O}_{2}$ /day. However, saturation is reached in this case as well and the oxygenation limit can only be confirmed with lower inlet oxygen concentrations which is expected to occur in the later stages of the experimental period (with the increase in bio-mass in the system).

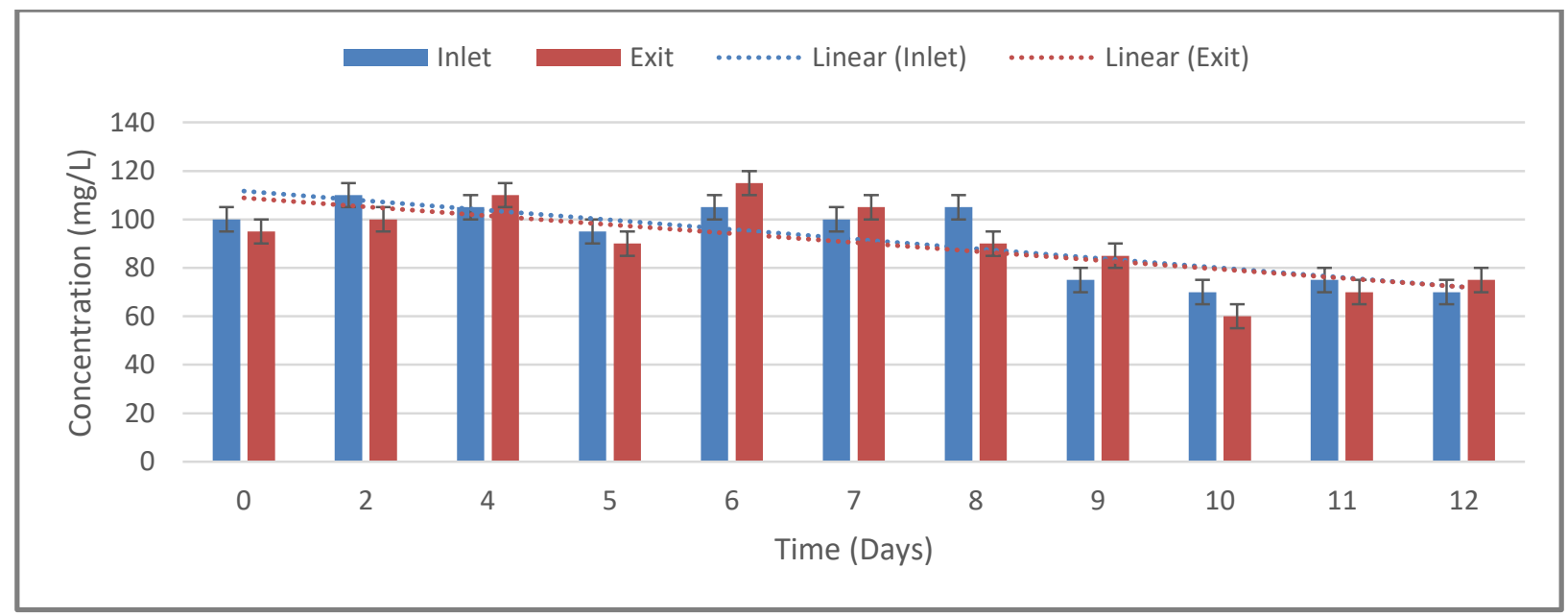

Fig. 4: Carbon dioxide reduction using $5.08 \mathrm{~cm}$ airlift pump .

Dissolved Carbon Dioxide was measured throughout the experiment at the inlets and outlets of the two pumps. A HACH test kit (Model CA-23) was used for the measurement. This test is a drop count titration test by collecting samples at the desired locations. Due to the nature of the test procedure, it is difficult to find with good accuracy, the $\mathrm{CO}_{2}$ stripping capacity of the pumps. However, Fig 3 show a clear decline in $\mathrm{CO}_{2}$ over a sample period in the experiment. This is interesting since the biological addition of $\mathrm{CO}_{2}$ to the system increases over time with the increase in biomass in the system. This iterates the positive effect of airlift pumps in aquaponics systems as a $\mathrm{CO}_{2}$ degasser. The validity of the results can further be strengthened by the fact that $2.54 \mathrm{~cm}$ pump shows the same overall decline (Fig 4). The limit of $\mathrm{CO}_{2}$ degassing by the airlift can be noted once the overall $\mathrm{CO}_{2}$ in the system start rising in the later stages of the experimental period.

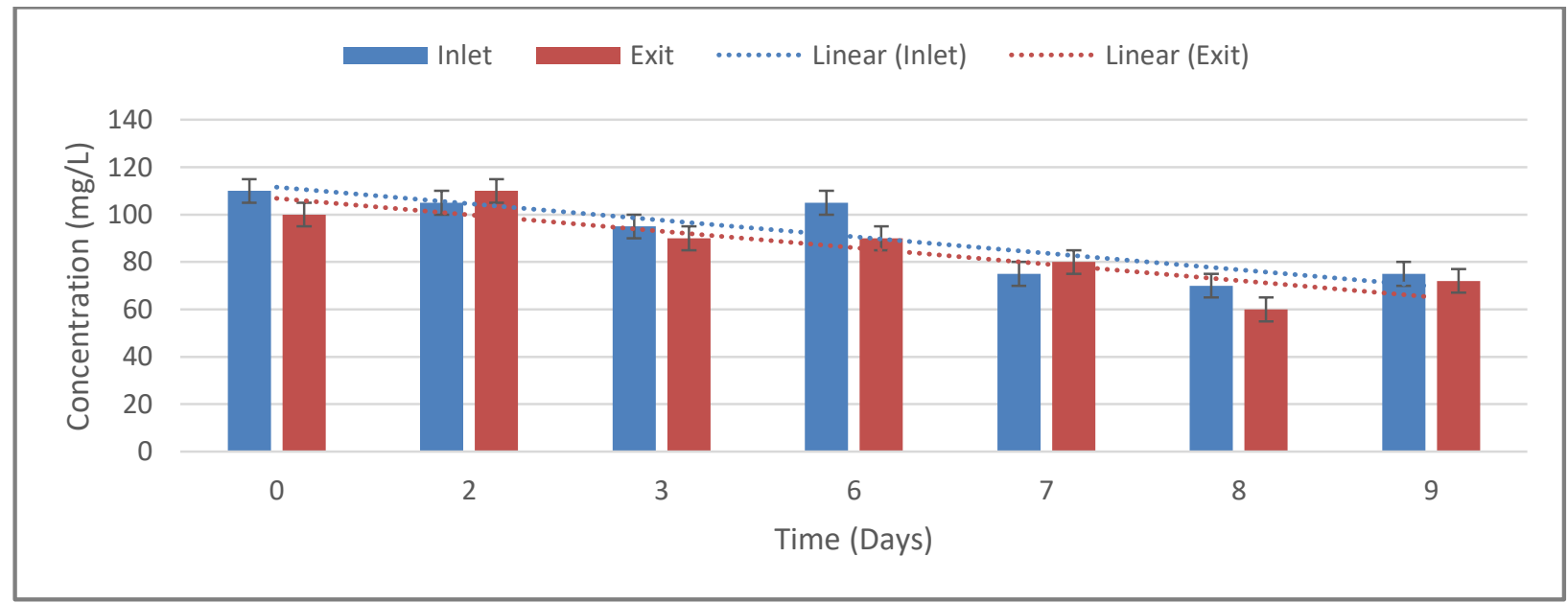

Fig. 5: Carbon dioxide degassing in a $2.54 \mathrm{~cm}$ airlift pump. 


\section{Conclusion}

The use of airlift pumps in biological systems found to provide aeration while simultaneously pumping water. The mass transfer specifically for oxygen transfer to the water in an aquaponics system is studied in this paper. Two pumps were used to provide aeration and water flow to two sub-systems; namely hydroponic loop and aquaculture loop. A 2.54 $\mathrm{cm}$ pump provides the requirements for the hydroponic loop while the $5.08 \mathrm{~cm}$ pump provides the requirements for the aquaculture loop. The $2.54 \mathrm{~cm}$ pump is consistently increasing the DO by $2.86 \pm 90 \mathrm{mg} / \mathrm{L}$ of oxygen to fully saturate the water. The $5.08 \mathrm{~cm}$ airlift pump on the other hand is increasing the DO by $2.70 \pm 0.25 \mathrm{mg} / \mathrm{L}$ of oxygen with an air injection of $124.6 \mathrm{LPM}$ to the airlift pump at submergence ratio of $45 \%$. The $2.54 \mathrm{~cm}$ pump is adding $3.65 \mathrm{~g} \mathrm{O}_{2} /$ day to the system while the $5.08 \mathrm{~cm}$ pump is adding $80.05 \mathrm{~g} \mathrm{O}_{2} /$ day to the system. The initial results show consistent mass transfer by the airlift pumps. There was an overall decline in the dissolved carbon dioxide in the system over time. This shows positive results on the carbon dioxide stripping capacity of FloNergia (C) airlift pump. However, additional data over longer period experiments is required to quantify the carbon dioxide stripping capacity of the pump.

\section{Acknowledgements}

The authors wish to acknowledge the support received from OMAFRA (Ontario Ministry of Agriculture and Rural Affairs) under the Gryphon's LAAIR (Leading to Accelerated Adoption of Innovative Research) grant. Also the support of Waterfarmers, FloNergia and Hagen Aqualab is greatly appreciated.

\section{References}

[1] W. H. Ahmed and H. M. Badr, "Dual-injection airlift pumps: An enhanced performance," Part. Sci. Technol., vol. 30, no. 6, pp. 497-516, 2012.

[2] W. H. Ahmed, A. M. Aman, H. M. Badr, and A. M. Al-Qutub, "Air injection methods: The key to a better performance of airlift pumps," Exp. Therm. Fluid Sci., 2016.

[3] R. Tyson, E. H. Simmone, J. M. White, and E. M. Lamb, "Reconciling Water Quality Parameters Impacting Nitrification in Aquaponics: the PH Level," Proc. Fla. State Hort. Soc., vol. 117, no. 117, pp. 79-83, 2004.

[4] C. Somerville, M. Cohen, E. Pantanella, A. Stankus, and A. Lovatelli, Small-scale aquaponic food production. Integrated fish and plant farming, 2014.

[5] T. Hussain, A. K., Verma, V. K. Tiwari, C. Prakash, G. Rathore, A. P. Shete, K. K. Nuwansi, "Effect of water flow rates on growth of Cyprinus carpio var. koi (Cyprinus carpio L., 1758) and spinach plant in aquaponic system," $J$. World Aquaculture Society, vol. 45 no. 6, pp. 652-661, 2014.

[6] M. B. Timmons and J. M. Ebeling, Recirculating Aquaculture Systems. Cayuga Aqua Ventures LLC, 2010.

[7] J. C. Loyless and R. F. Malone, "Evaluation of air-lift pump capabilities for water delivery, aeration, and degasification for application to recirculating aquaculture systems," Aquac. Eng., vol. 18, no. 18, pp. 117-133, 1998.

[8] B. Barrut, J. P. Blancheton, J. Y. Champagne, and A. Grasmick, "Mass transfer efficiency of a vacuum airliftApplication to water recycling in aquaculture systems," Aquac. Eng., vol. 46, no. 1, pp. 18-26, 2012.

[9] S. Z. Kassab, H. A. Kandil, H. A. Warda, and W. H. Ahmed, "Air-lift pumps characteristics under two-phase flow conditions," Int. J. Heat Fluid Flow, 2009. 